\title{
REVIEW
}

\section{The hypothalamic-pituitary-adrenal axis in childhood cancer survivors}

\author{
Christina Wei' and Elizabeth C Crowne ${ }^{2}$ \\ 'St George's University Hospital, NHS Foundation Trust, London, UK \\ 2Bristol Royal Hospital for Children, University Hospitals Bristol, NHS Foundation Trust, Bristol, UK \\ Correspondence should be addressed to E C Crowne: Liz.Crowne@UHBristol.nhs.uk
}

\begin{abstract}
Endocrine abnormalities are common among childhood cancer survivors. Abnormalities of the hypothalamic-pituitary-adrenal axis (HPAA) are relatively less common, but the consequences are severe if missed. Patients with tumours located and/or had surgery performed near the hypothalamic-pituitary region and those treated with an accumulative cranial radiotherapy dose of over $30 \mathrm{~Gy}$ are most at risk of adrenocorticotrophic hormone (ACTH) deficiency. Primary adrenal insufficiency may occur in patients with tumours located in or involving one or both adrenals. The effects of adjunct therapies also need to be considered, particularly, new immunotherapies. High-dose and/or prolonged courses of glucocorticoid treatment can result in secondary adrenal insufficiency, which may take months to resolve and hence reassessment is important to ensure patients are not left on long-term replacement steroids inappropriately. The prevalence and cumulative incidences of HPAA dysfunction are difficult to quantify because of its non-specific presentation and lack of consensus regarding its investigations. The insulin tolerance test remains the gold standard for the diagnosis of central cortisol deficiency, but due to its risks, alternative methods with reduced diagnostic sensitivities are often used and must be interpreted with caution. ACTH deficiency may develop many years after the completion of oncological treatment alongside other pituitary hormone deficiencies. It is essential that health professionals involved in the long-term follow-up of childhood cancer survivors are aware of individuals at risk of developing HPAA dysfunction and implement appropriate monitoring and treatment.
\end{abstract} Key Words

Endocrine-Related Cancer (2018) 25, R479-R496

\section{Introduction}

Improvement in paediatric oncology treatment and support have overseen the dramatic increase in overall 5-year survival rates of all childhood cancers from less than 30\% in the 1960 s to the current $>80 \%$ in the United Kingdom (https://www.cancerresearchuk.org/health-professional/ cancer-statistics/childrens-cancers/long-term-followup\#heading-Two). An estimated 1 in 640-700 young adults in the United States and United Kingdom is a childhood cancer survivor (Campbell et al. 2004, Oeffinger et al. 2006). Unfortunately, survival comes with a cost, and there is ample evidence that childhood cancer survivors experience adverse physical, psychological and social health problems later in life, as well as premature mortality. Data from the United States, United Kingdom and Northern Europe have demonstrated a high relative risk of death with a standardised mortality rate of 8.3-10.8 in childhood cancer 
survivors (Oeffinger et al. 2006, Mertens et al. 2008, Diller et al. 2009, Reulen et al. 2010, Garwicz et al. 2012). About three-quarters of patients were reported to have at least one chronic health condition and over two-fifths were affected by severe, disabling or life-threatening conditions or have died from chronic conditions within 30 years of diagnosis (Oeffinger et al. 2006).

In the United Kingdom, approximately 1800 new cases of cancer are diagnosed in children per year. Leukaemia is the most common childhood malignancy, followed by intracranial central nervous system (CNS) tumours and lymphoma. Other malignant conditions specific to children include neuroblastoma and nephroblastoma (Wilms' Tumour). As the population of childhood cancer survivors increases, emphasis on the management of the long-term health becomes more important with aims to prevent early morbidity and mortality. Around $50 \%$ of childhood cancer survivors develop one or more endocrine disorders with a higher risk among those treated for tumours of the CNS and the prevalence increases over time (Patterson et al. 2012, Brignardello et al. 2013, Mostoufi-Moab et al. 2016). Abnormalities of the hypothalamic-pituitary-adrenal axis (HPAA) are relatively less common in childhood cancer survivors compared with other endocrine disorders such as growth hormone deficiency, gonadal failure and hypothyroidism, but there can be a significant impact on morbidity and mortality risk (Rose et al. 2004). Under physiological stress, undiagnosed cortisol deficiency may present with life-threatening adrenal crisis. On a day-to-day basis, patients with adrenal insufficiency can experience subtle and non-specific symptoms such as fatigue, which are easily dismissed and result in a reduced quality of life.

This review provides an overview of risk factors, surveillance methods and future directions needed in the research of HPAA dysfunction in childhood cancer survivors under the following headings:

Risk factors for HPAA dysfunction:

1. The primary diagnosis: location and type of cancer

- CNS tumours at the hypothalamic-pituitary (HP) region

- Adrenal tumours

2. Treatment modality

- Radiotherapy

o Accumulative dose and fractionation schedule

o Location - cranial irradiation to tumours in HP region and its proximity

o Location - cranial irradiation for malignancies not specifically involving the HP region or its proximity o Type of radiotherapy

- Chemotherapy

- Glucocorticoid therapy

- Immunotherapy

- Oncology treatment and autoimmune diseases

3. Patient factors

- Assessment of HPAA in childhood cancer survivors

- Relationship between HPAA function and wider aspects of health

- Future directions

\section{Risk factors for HPAA dysfunction}

Table 1 summarises key publications with data concerning HPAA dysfunction in childhood cancer survivors. The relevant studies are categorised according to the location of the primary tumour. However, the majority of the studies are limited by heterogeneity in patient characteristics such as the primary diagnosis, treatment modalities, age of treatment and follow-up time post treatment, as well as the method of assessment and definition of HPAA dysfunction.

\section{The primary diagnosis: location and type of cancer}

Unsurprisingly, tumours within or close to the HP region, and those of the adrenal glands can have a direct impact on HPAA function either as a result of the primary tumour or its treatment.

\section{CNS tumours at the HP region}

Intracranial tumours involving the $\mathrm{HP}$ region either directly or in its vicinity, such as the optic pathway, may result in central HPAA dysfunction at diagnosis as a result of local damage and/or after neurosurgery, with potentials for evolving effects over time from possible further tumour growth or after cranial irradiation (Fig. 1). Tumours at the suprasellar and intrasellar regions account for $10 \%$ of all CNS tumours in childhood (Arora et al. 2009). Abnormalities in endocrine function are often already present at diagnosis (Tan et al. 2017). The most common forms of childhood HP tumours are gliomas and craniopharyngiomas.

Gliomas - tumours derived from glial cells - are classified according to grade (low and high) and location. There is limited research distinguishing longterm sequelae caused by the tumour location from its treatment. Low-grade brain tumours such as HP lowgrade astrocytoma may have an indolent course for many 

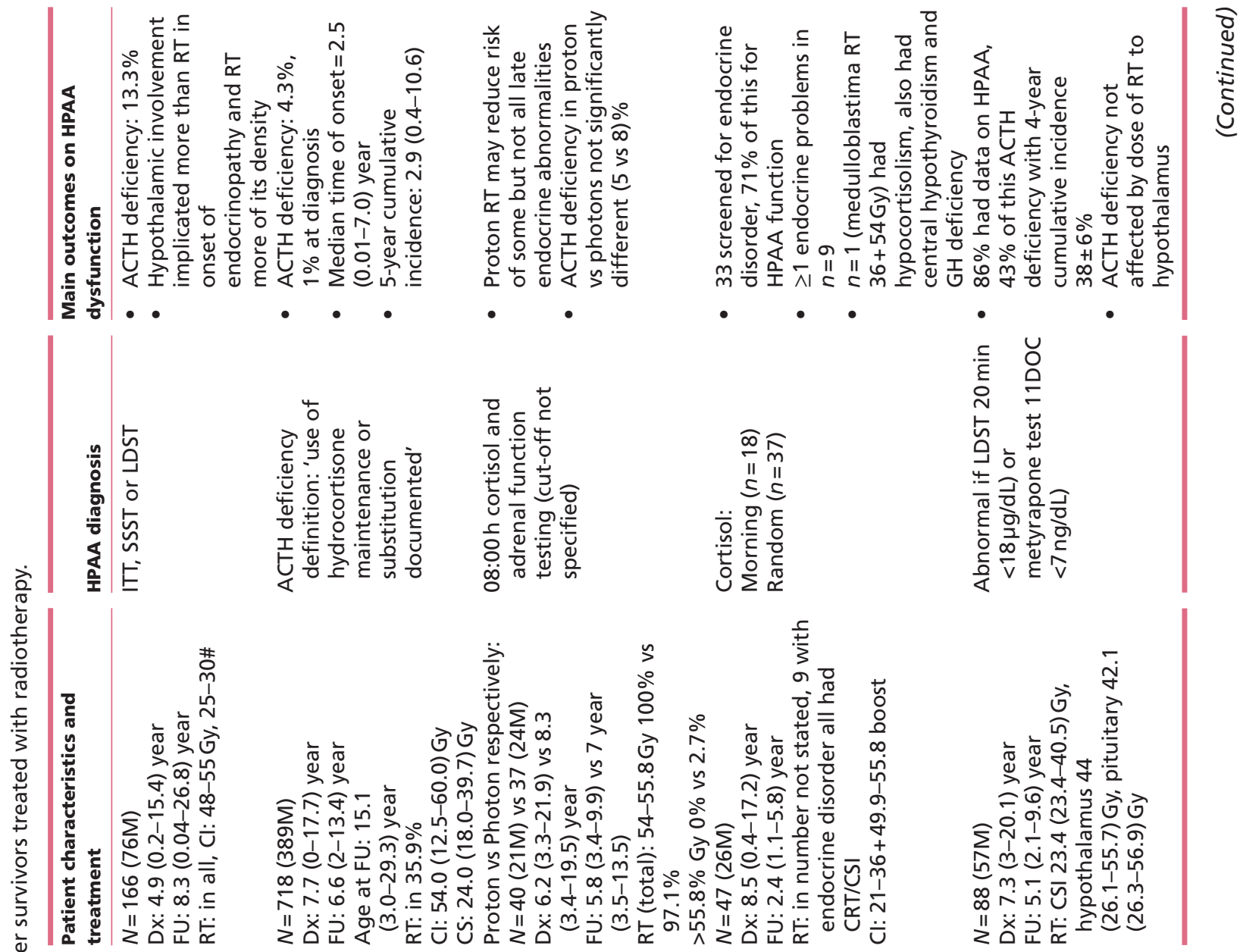

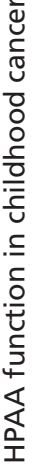
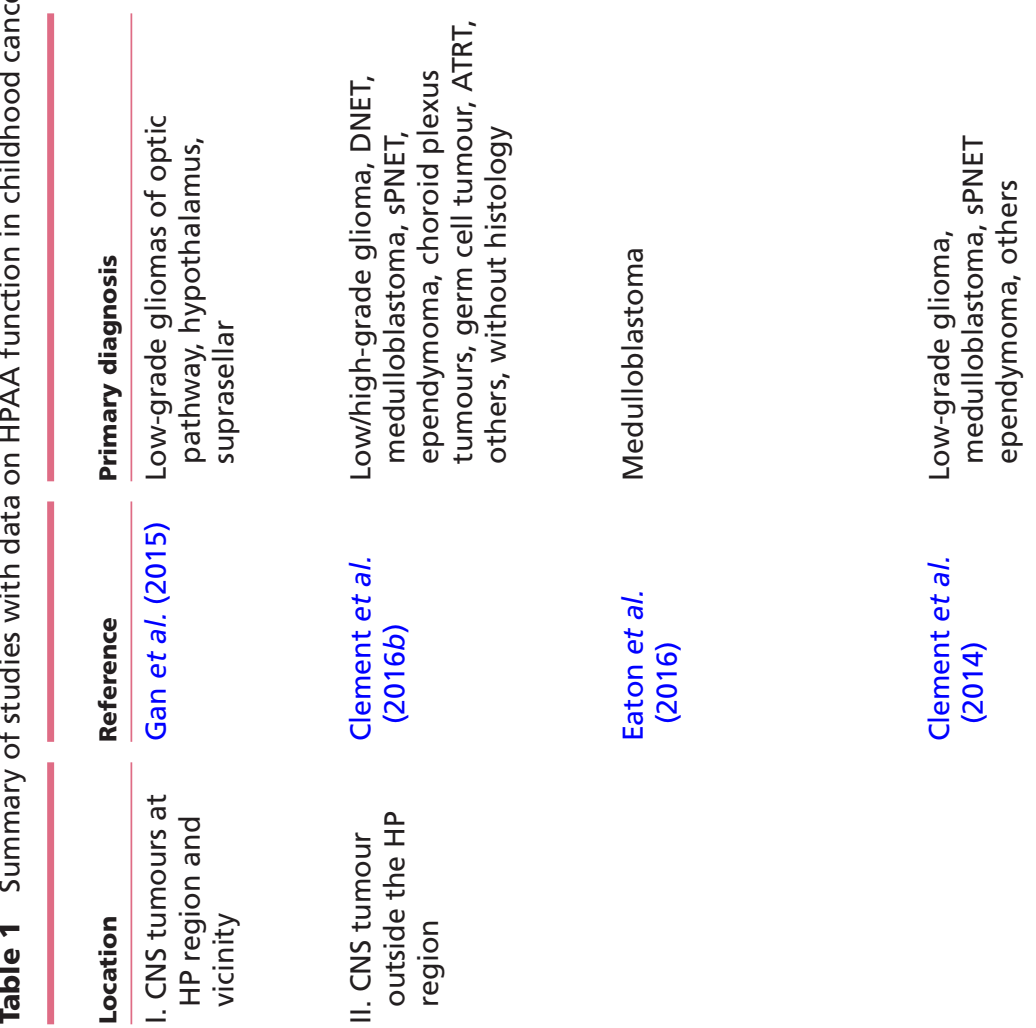
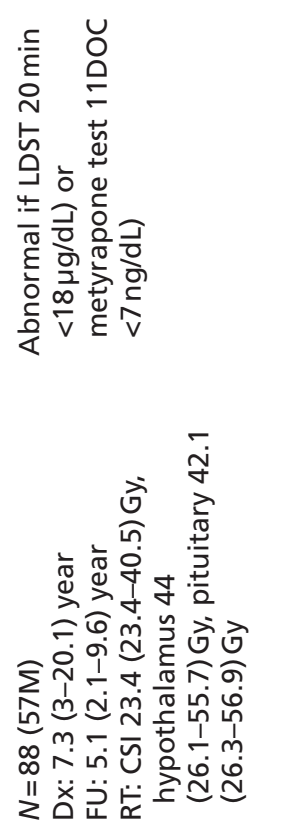
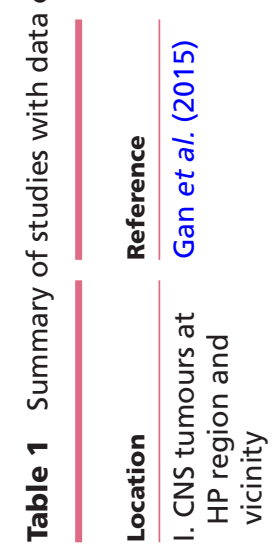
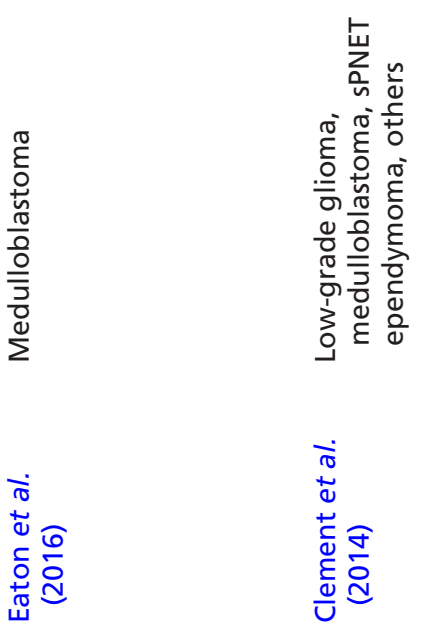
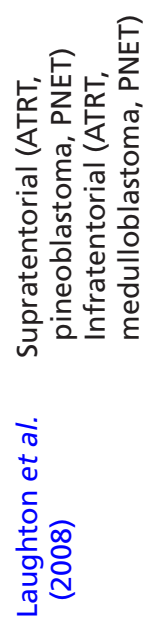


\section{Cancer}
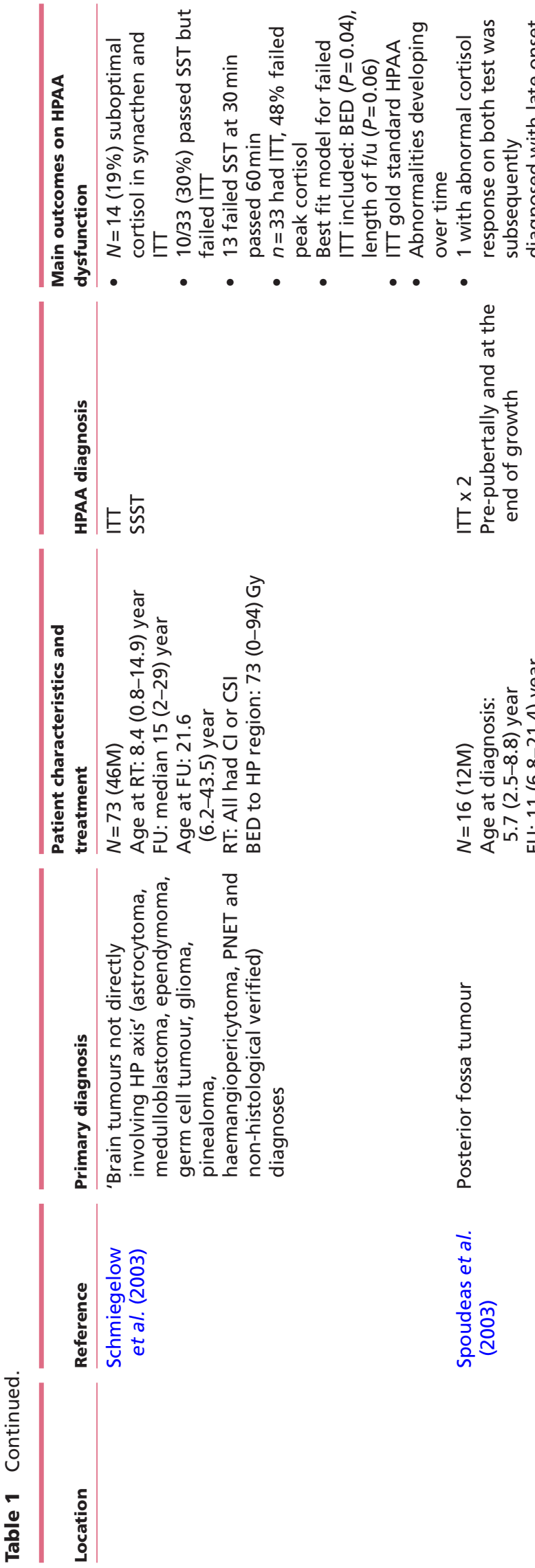

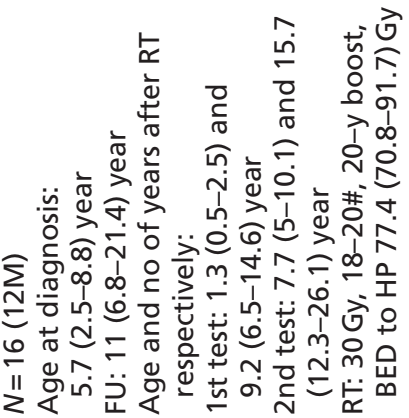

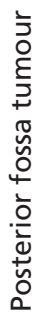
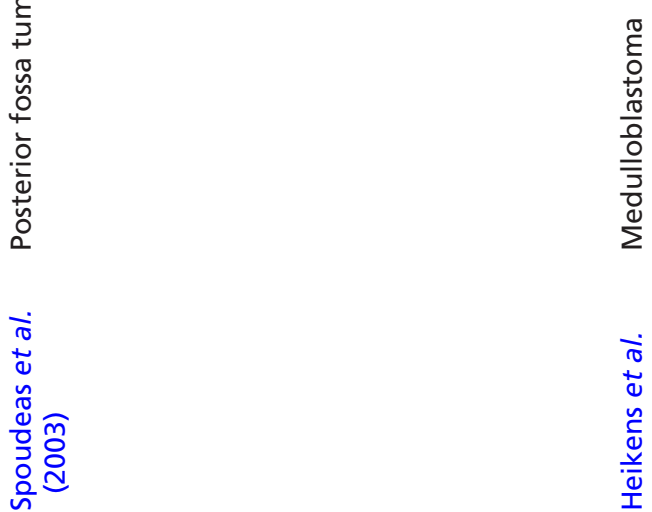
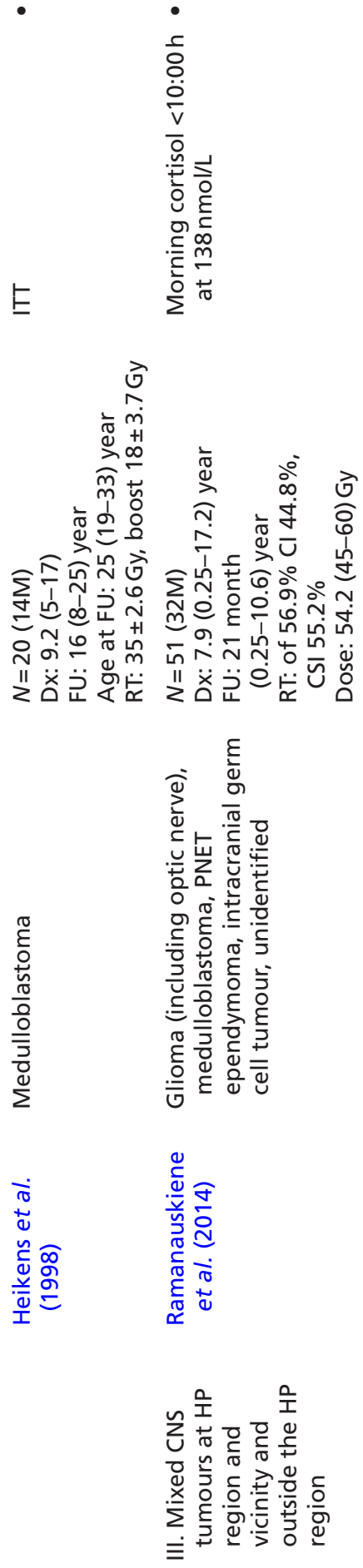

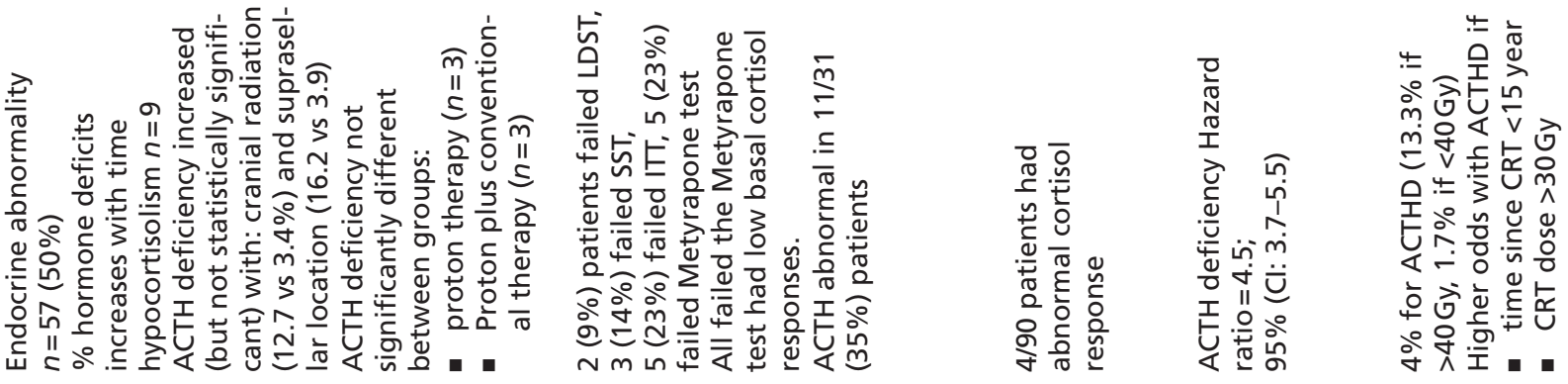

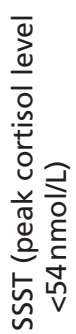
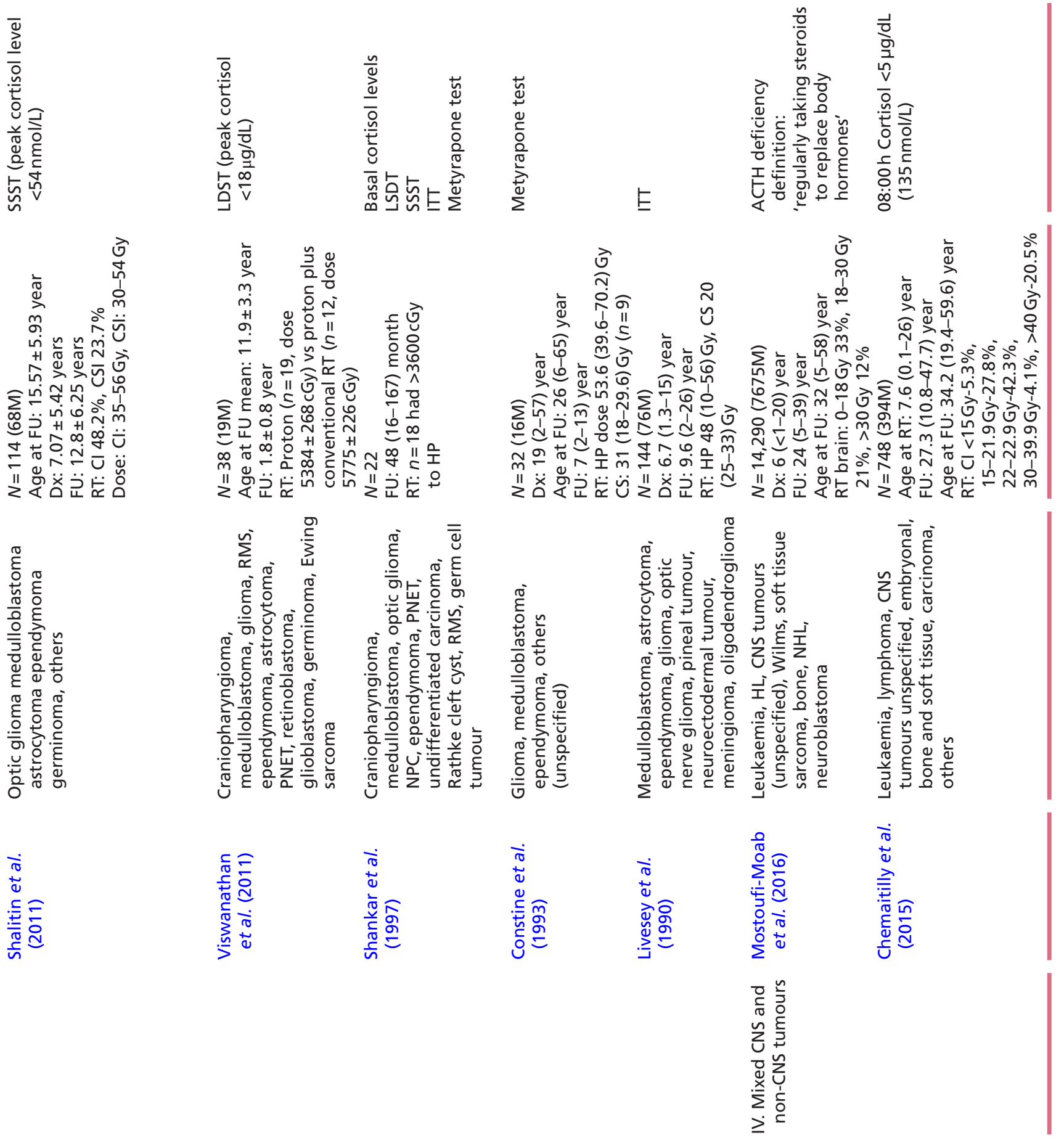

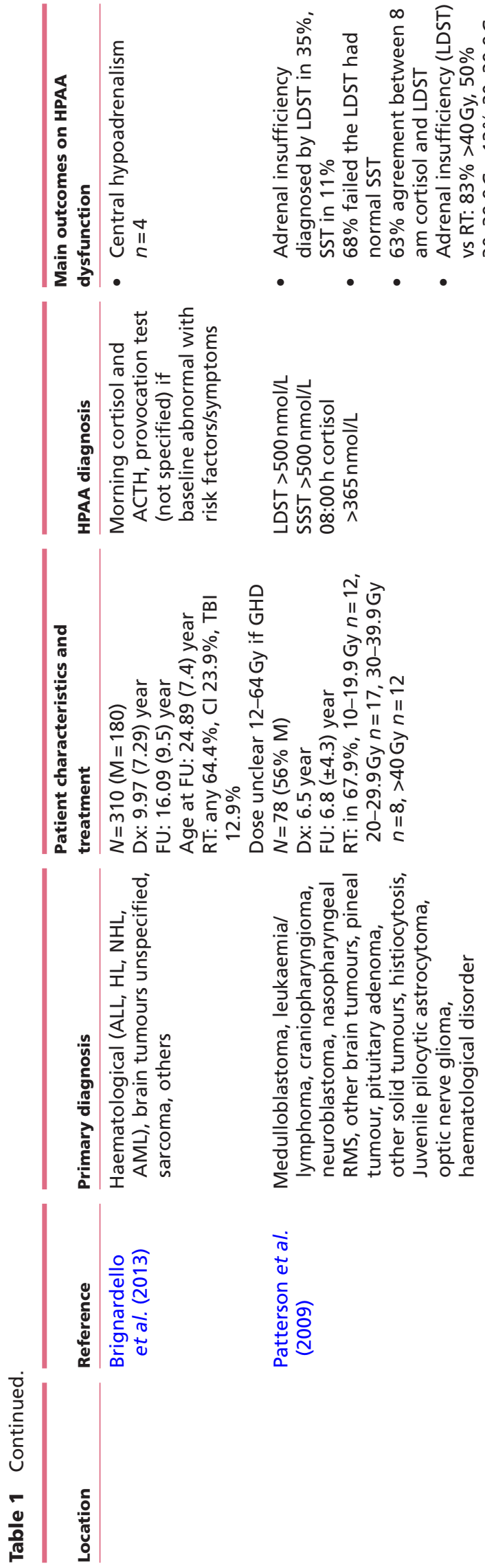
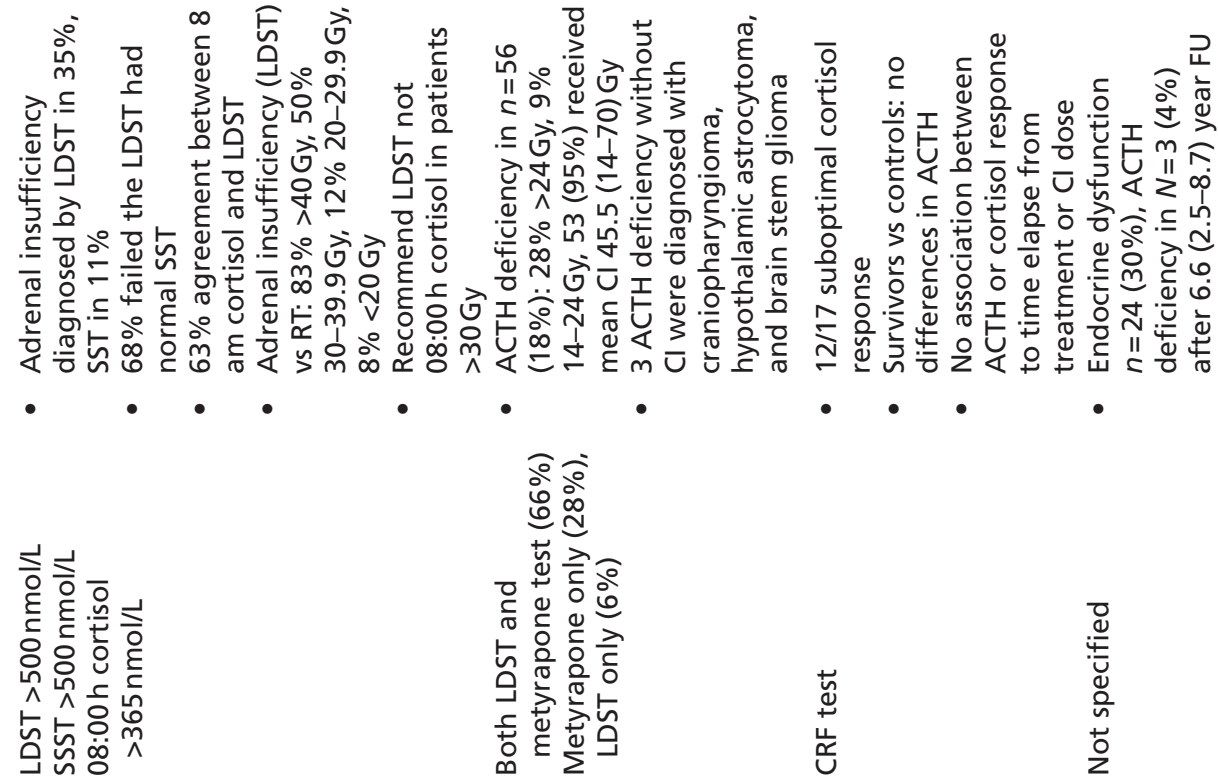

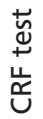

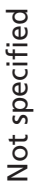
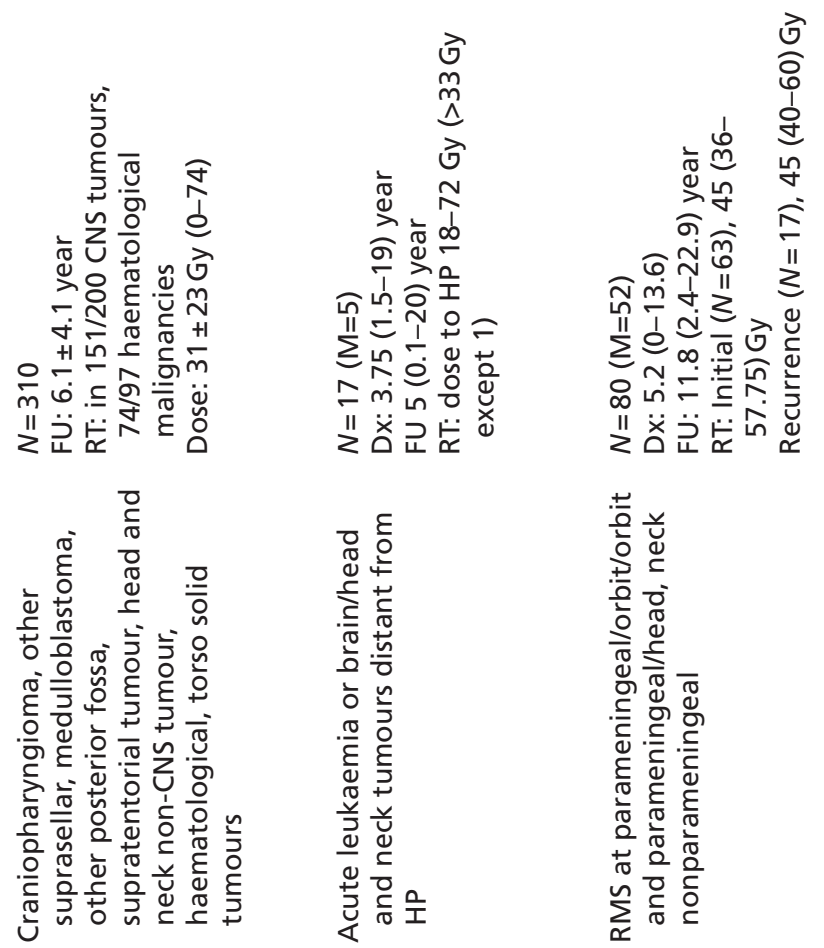

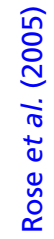
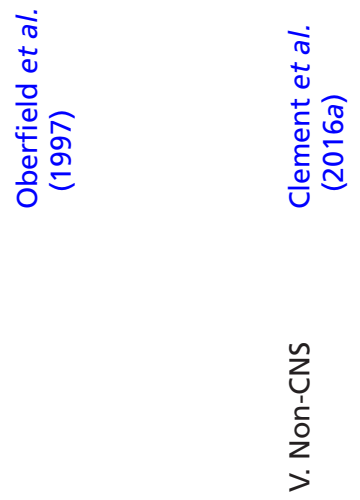

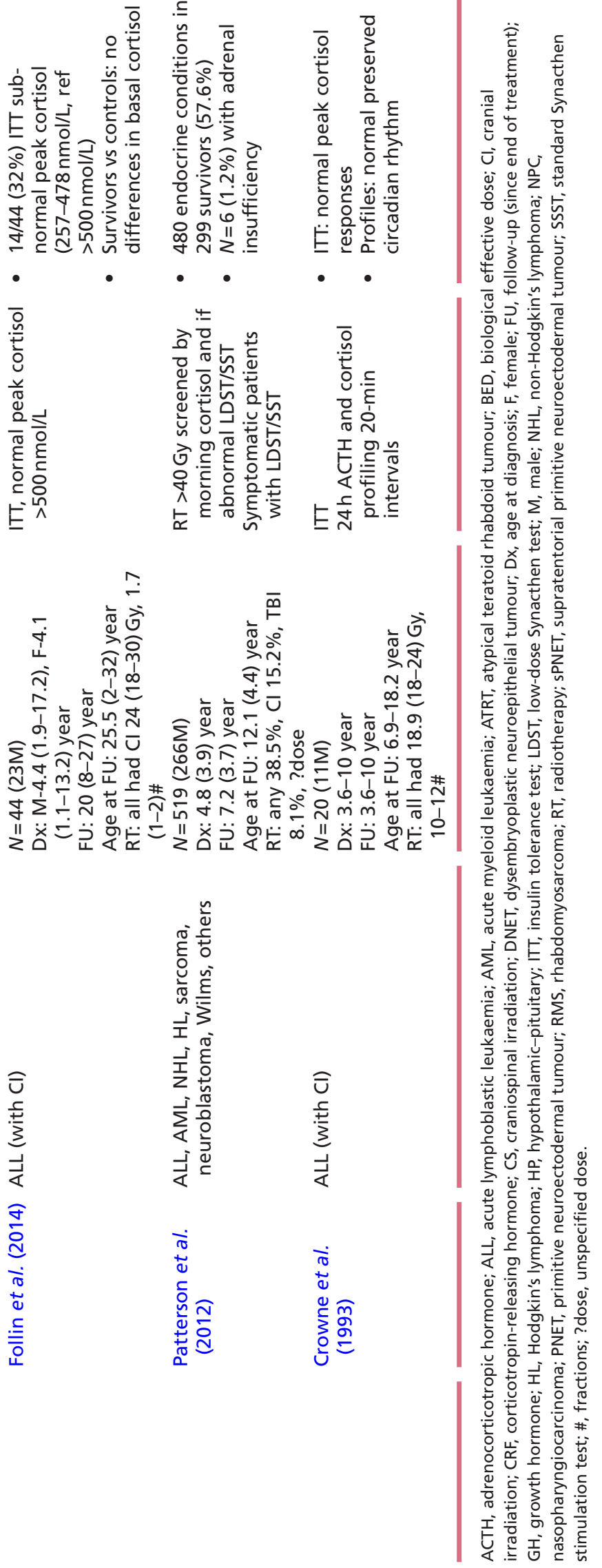

years with potential for progressive HP dysfunction. Gan et al. reported adrenocorticotrophic hormone (ACTH) deficiency in $13.3 \%$ of 166 cases of childhood glioma affecting the optic pathway, hypothalamus, suprasellar region and crucially demonstrated hypothalamic involvement or the presence of diencephalic syndrome as key predictors of the onset of most endocrine dysfunction (Gan et al. 2015). Diencephalic syndrome, in particular, was reported as an independent positive predictor for ACTH deficiency with a hazard ratio of 15.7. Reversible HPAA dysfunction was found in two patients possibly secondary to dexamethasone suppression (Gan et al. 2015).

Craniopharyngiomas are suprasellar tumours derived from embryonic tissues and may present with endocrine abnormalities such as growth failure and pubertal disorders even before surgical interventions. ACTH deficiency in childhood survivors of craniopharyngiomas is common after surgery, but the prevalence has reduced more recently as treatment preference moves towards less invasive surgery with the use of adjuvant therapies such as radiotherapy and chemotherapy. Cohen et al. compared endocrine outcomes of childhood craniopharyngioma survivors diagnosed over a 30-year period and reported a lower, but still substantial prevalence of ACTH deficiency of $64 \%$ at follow-up in those diagnosed between 2001 and 2010 compared with 95\% from 1991 to 2000 (Cohen et al. 2013).

HPAA dysfunction may also occur in patients with nonCNS cranial tumours at close proximity to the HP region (e.g. rhabdomyosarcoma at the orbital and nasopharynx) and brain tumours distant from the HP region (e.g. medulloblastoma) as a result of their treatment. This is discussed later under treatment modality.

\section{Adrenal tumours}

Primary adrenal tumours are very rare in children, but it is key to establish the extent of any surgery involving the adrenal glands or abdominal masses, which could involve adrenals. Surgical resection of one or both adrenals may occur in the management of neuroblastoma, nephroblastoma and phaeochromocytoma. Neuroblastomas (primary adrenal medulla tumours), which originate from immature neuroblasts and secrete catecholamine precursors, are treated by surgery and radiotherapy, with the addition of chemotherapy and autologous stem cell rescue if metastasis is present. Nephroblastomas are associated with an abnormal proliferation of embryonic kidney cells (metanephroma) 


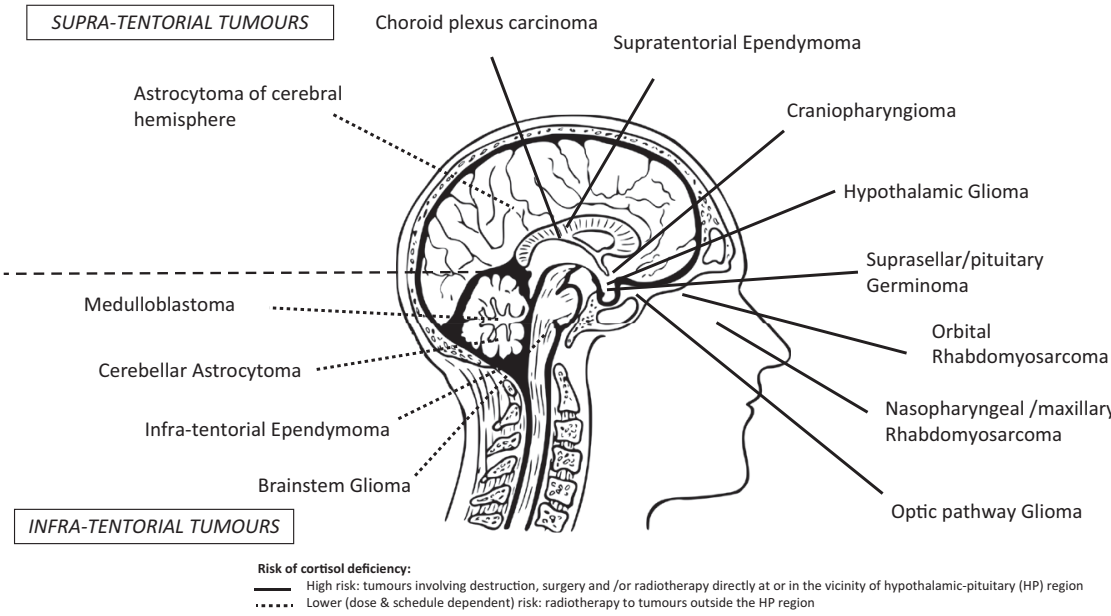

\section{Figure 1}

Common sites for cranial tumours in children who are commonly treated with radiotherapy. and may present as a large abdominal mass, treated primarily by surgery, i.e. nephrectomy, which may also include adrenalectomy, followed by chemotherapy. Postoperative radiotherapy to the flanks is given to cases with incomplete resection or metastasis. Normal adrenal function with compensatory increase in baseline ACTH and cortisol levels had been demonstrated in childhood survivors of neuroblastoma and nephroblastoma after unilateral adrenalectomy (van Waas et al. 2012), but there are limited data on the effects of abdominal irradiation on the adrenal glands (Bölling et al. 2010). Childhood adrenocortical carcinoma is very rare and may be sporadic or part of a genetic syndrome such as Carney Complex, Li Fraumeni and MEN type 1. The risk of cortisol deficiency after surgical resection, or additional treatment with chemotherapy, radiotherapy and hormone therapy is obviously significant and requires investigation.

\section{Treatment modality}

In addition to the direct effects from tumour destruction and surgical resection, other treatment modalities such as radiotherapy, chemotherapy and immunotherapy may also lead to endocrine dysfunction. Radiotherapy is the most commonly implicated treatment modality in longterm HP dysfunction, and its effects are known to be dose and schedule dependent. This applies not only to tumours in the HP region, but also those in the vicinity or further away where the bio-equivalent dose (BED) to the HP region is inevitably still significant. There is limited evidence of any effect on HPAA function from adjunct standard chemotherapy, but emerging evidence of significant endocrine problems after immunotherapy.

\section{Radiotherapy}

The impact of radiotherapy on the HP axis is well established. Compared with other pituitary hormone axes, the HPAA is more resistant to radiation-induced damage. Nevertheless, the risk of HPAA dysfunction is not negligible as studies specific to survivors treated with cranial irradiation have reported a prevalence of up to 43\% (Laughton et al. 2008) (Table 1). The risk of HPAA dysfunction is associated with the accumulative dose, fractionation schedule, location and type of radiation. Current recommended radiotherapy regimens of the common paediatric tumours in the United Kingdom are summarised in Table 2 (British Neuro-Oncology Society 2011, Royal College of Radiologists 2016). The biological effects of different radiation schedules can be quantified more precisely by linear quadratic model mathematically to calculate the BED of irradiation and therefore assessment of the impact to specific tissues such as the hypothalamic and/or pituitary function (Schmiegelow et al. 2000, Jones et al. 2001). However, this information is not always available.

Accumulative dose and fractionation schedule The risk of HP dysfunction post cranial irradiation is dose dependent and increases with increased accumulative dosage. The Childhood Cancer Survivor Study showed that ACTH deficiency occurred significantly more often after hypothalamic irradiation of greater than $30 \mathrm{~Gy}$ compared with survivors exposed to 0-30Gy, with a hazard ratio of 4.5 (95\% CI, 3.7-5.5) (Mostoufi-Moab et al. 2016). In a mixed cohort of survivors treated with cranial irradiation, Patterson et al. showed increased prevalence of abnormal adrenal function by low-dose Synacthen test with progressive increase in radiation dose: $8 \%$ : 
Table 2 Radiotherapy dose and fractionation schedules of common childhood cancers.

\begin{tabular}{|c|c|c|c|}
\hline Site & Malignancy & Dose & $\begin{array}{c}\text { No of fractions \# (over } \\
\text { weeks/days) }\end{array}$ \\
\hline \multirow[t]{28}{*}{ CNS } & Low-grade astrocytomaa & 54Gy & 30\# (6 week) \\
\hline & & Spinal: $50.4 \mathrm{~Gy}$ & $28 \#(5.5$ week $)$ \\
\hline & High-grade astrocytomaa & $<14$ year: $54 \mathrm{~Gy}$ & 30\# (6 week) \\
\hline & & >14 year: $60 \mathrm{~Gy}$ & 30\# (6 week) \\
\hline & Ependymoma & $59.4 \mathrm{~Gy}$ & 33\# (6.5 week) \\
\hline & Medulloblastomaa & $\begin{array}{l}\text { Standard risk: } \\
\text { Medulloblastoma/PNET }\end{array}$ & \\
\hline & & $23.4 \mathrm{~Gy}+$ boost to tumour bed/posterior fossa & 13\# (2.5 week) \\
\hline & & $30.6 \mathrm{~Gy}$ & $17 \#$ (3.5 week) \\
\hline & & $\begin{array}{l}\text { High risk medulloblastoma and Supratentorial } \\
\text { PNET: }\end{array}$ & \\
\hline & & 36 Gy & 20\# (4 week) \\
\hline & & 39.6 Gy (M2-3) & 22\# (4.4 week) \\
\hline & & Boost to primary sites: & in $1.8 \mathrm{~Gy}$ \\
\hline & & $54-55.8 \mathrm{~Gy}$ & \\
\hline & & Boost to metastatic sites: $50.4 \mathrm{~Gy}$ (spinal) & in $1.8 \mathrm{~Gy}$ \\
\hline & & 54-55.8 Gy (intracranial) & \\
\hline & Germinomaa & No chemotherapy: & \\
\hline & & 24Gy & 15\# (3 week) \\
\hline & & $16 \mathrm{~Gy}$ & $10 \#(2$ week $)$ \\
\hline & & Post chemotherapy: & \\
\hline & & $24 \mathrm{~Gy}$ & 15\# (3 week) \\
\hline & & Boost to residual disease & \\
\hline & & $16 \mathrm{~Gy}$ & 10\# (2 week) \\
\hline & & Non-germinomatous & \\
\hline & & 54 Gy & 30\# (6 week) \\
\hline & & Meningeal metastasis & \\
\hline & & $30 \mathrm{~Gy}$ & 20\# (4 week) \\
\hline & Brain stem gliomaa & $54 \mathrm{~Gy}$ & $30 \#(6$ week) \\
\hline & Craniopharingiomaa & $50-55$ Gy or 52.2-54 Gy & $\begin{array}{l}\text { 30-33\# (6-6.5 week) } \\
\text { 27-28\# (5.5 week) }\end{array}$ \\
\hline \multirow[t]{9}{*}{ Orbit/nasopharynx } & Rhabdomyosarcoma ${ }^{a}$ & Embryonic: & \\
\hline & & No surgery & \\
\hline & & Complete response to chemotherapy: $41.4 \mathrm{~Gy}$ * & $23 \#$ of $1.8 \mathrm{~Gy}$ \\
\hline & & $\begin{array}{l}\text { Incomplete response to chemotherapy: } \\
50.4 \mathrm{~Gy}^{*}\end{array}$ & $28 \#$ of $1.8 \mathrm{~Gy}$ \\
\hline & & Surgery: $36 \mathrm{~Gy}$ & $20 \#$ of $1.8 \mathrm{~Gy}$ \\
\hline & & Alveolar & \\
\hline & & No surgery: $50.4 \mathrm{~Gy} *$ & $28 \#$ of $1.8 \mathrm{~Gy}$ \\
\hline & & Surgery: $41.1 \mathrm{~Gy}$ & $23 \#$ of $1.8 \mathrm{~Gy}$ \\
\hline & & ${ }^{*} \pm 5.4 \mathrm{~Gy}$ for large tumours/poor response & $3 \#$ of $1.8 \mathrm{~Gy}$ \\
\hline \multirow[t]{5}{*}{ Orbit } & Optic pathway gliomab & Brain: 35 Gy & $21 \#$ of $1.67 \mathrm{~Gy}$ \\
\hline & & Spine: $35 \mathrm{~Gy}$ & $21 \#$ of $1.67 \mathrm{~Gy}$ \\
\hline & & Boost for metastasis & \\
\hline & & Intracranial: $20 \mathrm{~Gy}$ & $12 \#$ of $1.67 \mathrm{~Gy}$ \\
\hline & & Spinal metastatic: $15 \mathrm{~Gy}$ & 9\# of $1.67 \mathrm{~Gy}$ \\
\hline \multirow[t]{3}{*}{ Leukaemia } & Leukaemia (cranial)a & $24 \mathrm{~Gy}$ & 15\# (3 week) \\
\hline & Leukaemia (TBI for HSCT)a & $14.4 \mathrm{~Gy}$ & 8\# (4 day) \\
\hline & Leukaemia (CNS cranial boost)a & $5.4 \mathrm{~Gy}$ & 3\# (3 day) \\
\hline \multirow[t]{6}{*}{ Abdominal } & Neuroblastomaa & $21 \mathrm{~Gy}$ & 14\# (3 week) \\
\hline & Wilms tumoura & Intermediate risk: $14.4 \mathrm{~Gy}$ & 8\# (1.5 week) \\
\hline & & High risk $25.2 \mathrm{~Gy}$ & 14\# (2 week) \\
\hline & & Whole abdomen $21 \mathrm{~Gy}$ & 14\# (2 week) \\
\hline & & Boost to macroscopic disease/nodes: $10.8 \mathrm{~Gy}$ & 6\# (2 week) \\
\hline & & Whole lung: $15 \mathrm{~Gy}$ & 10 (2 week) \\
\hline
\end{tabular}

aRoyal College of Radiologists (2016); bBritish Neuro-Oncology Society (2011).

http://erc.endocrinology-journals.org https://doi.org/10.1530/ERC-18-0217
() 2018 Society for Endocrinology Published by Bioscientifica Ltd. Printed in Great Britain 
<20 Gy, 12\%: 20-29.9 Gy, 50\%: 30-39.9 Gy, 83\%: >40 Gy (Patterson et al. 2009).

Radiation-induced toxicity is also dependent on the fractionation schedule that is the fraction size and the time allowed between fractions for normal tissue to repair (Mostoufi-Moab \& Grimberg 2010). Most radiation schedules use less than $2 \mathrm{~Gy}$ per fraction and no more than 5 fractions per week to minimise the damage to healthy neuronal tissues. Higher radiation doses of $>2 \mathrm{~Gy}$ per fraction (for the same total dose) can induce relatively more injury to the later-responding (neuronal) than the early-responding (tumour) tissues (Darzy \& Shalet 2009). However, previous trials comparing hyper-fractionated (e.g. splitting the usual radiotherapy dose to twice a day) with conventional radiotherapy regimens in paediatric oncology have not shown a difference in late toxicity (Paulino 2013).

\section{Location - cranial irradiation to tumours in HP region} and its proximity Cranial radiotherapy is widely used in the treatment of HP brain tumours and non-CNS cranial solid tumours in its proximity (e.g. orbital, nasal, pharyngeal rhabdomyosarcomas) (Fig. 1 and Table 1). Typical doses of cranial radiotherapy are 30-50 Gy over 3-5 weeks depending on the diagnosis and extent of the disease, and additional radiation ('boost') doses may be required in some metastatic tumours or residual disease post neurosurgery (Table 2). The effects of the total accumulative dose are high enough to result in HP dysfunction including ACTH deficiency in some patients (Clement et al. 2016a).

Gan et al. reported primary radiotherapy as an independent predictor for ACTH deficiency in tumours affecting the hypothalamus and its vicinity with a hazard ratio of 5.2 (Gan et al. 2015). A high risk of HPAA dysfunction is expected in childhood cancer survivors with tumour involving at the HP gland directly, studies have also shown that CNS tumours in the vicinity of the HP region (Fig. 1) also involve a significant BED to the HP region (Table 1).

\section{Location - cranial irradiation for malignancies not specifically involving the HP region or its} proximity Cranial irradiation that is given to some malignancies outside the HP region may still have a significant impact on HP function. Whole brain radiotherapy is delivered in high doses to a number of non-HP CNS tumours. Cranial irradiation of 18-24Gy was also given routinely in the past to children with acute lymphoblastic leukaemia as prophylaxis against
CNS relapse, but this is now reserved for cases with CNS disease. Total body irradiation of 10-16 Gy in 3-8 fractions is used as part of conditioning prior haematopoietic stem cell transplantation (HSCT) in some haematological malignancies such as acute lymphoblastic leukaemia. There is a large variation in the prevalence of HPAA dysfunction from such radiotherapy dose to the HP region reported in the literature, which is largely depending on the study population (Fig. 1 and Table 1).

Section II in Table 1 shows outcomes of ACTH deficiency in studies of CNS tumours not involving the HP region, but treated with radiotherapy. Laughton et al. reported a significant $43 \%$ prevalence of ACTH deficiency using the low-dose Synacthen stimulation test (LDST) in a mixed cohort of supra and infratentorial tumours distant from the HP region treated with a HP radiation BED of $>40$ Gy (Laughton et al. 2008). Schmiegelow et al. reported suboptimal cortisol response by insulin tolerance test (ITT) or LDST in $19 \%$ of childhood cancer survivors with brain tumours not directly involving the HP axis at a median follow-up of 15 years, who were treated with a BED of 73 (0-94) Gy to the HP region (Schmiegelow et al. 2003). However, ACTH deficiency was less common in other studies. Spoudeas et al. reported 3 out of 16 survivors of posterior tumour fossa tumours with suboptimal peak cortisol repose by ITT after 15.7-year follow-up, but one was later diagnosed with congenital adrenal hyperplasia and the other 2 had normal basal cortisol responses and subsequent normal results from LDST (Spoudeas et al. 2003). Heikens et al. also reported no cases of HPAA dysfunction among 20 childhood survivors of medulloblastoma by ITT (Heikens et al. 1998). It is difficult to extrapolate outcomes from some studies, which include mixed patient cohorts treated with and without radiotherapy (Clement et al. 2014, 2016b) and others with both HP and non-HP CNS tumours and/or non-CNS tumours, which did not report outcomes separately according to tumour location (Table 1, section III and IV).

The other main group of non-HP malignancies treated with cranial irradiation are the historical survivors of childhood lymphoblastic leukaemia (Table 1, section V). The risk of HPAA dysfunction of this group is multifactorial such as the time elapsed from treatment, dose of radiation and fractionation. Crowne et al. did not show the presence of ACTH deficiency after 4-10 years of follow-up (Crowne et al. 1993), whereas a high prevalence of $14 / 44(32 \%)$ was reported in survivors 20 years post treatment by Follin et al. (2014). However, survivors in the latter study received significantly higher doses of CI 
in fewer fractions (Follin et al. vs Crowne et al. $=24 \mathrm{~Gy}$ in 1-2 fractions vs $18.9 \mathrm{~Gy}$ in $10-12$ fractions, respectively; Crowne et al. 1993, Follin et al. 2014).

Type of radiotherapy Radiotherapy for cancer treatment involves the use of ionising radiation to kill or stop the replication of cancer cells. The most common modality of external beam radiation therapies are electromagnetic rays (i.e. photon beams from X-rays and gamma rays) and particle radiation (i.e. protons, neutrons, electrons) generated by linear acceleration.

Until recently, photon beams have been most widely used in the treatment of childhood cancer. Energy from photons deposit dose along the entire beam path where maximum dose is delivered just below the skin surface and continues until it exits the body. The newer proton radiotherapy uses protons, the positively charged particles from the atomic nucleus. Proton beams deliver the maximum dose of radiotherapy at the end of the path in a well-defined peak localised to the tumour (known as Bragg peak). There is minimal amount of energy deposited along the rest of the path, which therefore reduces radiation exposure to large volumes of normal tissues (Fig. 2).

Data comparing the long-term outcomes in childhood cancer survivors treated with proton therapy with conventional therapy are beginning to emerge. Eaton et al. (2016) investigated the prevalence of endocrine abnormalities in 77 children with medulloblastoma who were treated with chemotherapy and proton $(n=40)$ or photon $(n=37)$ radiation with median follow-up of 5.8 and 7 years. The study found that proton radiotherapy may reduce the risk of some, but not all radiation-associated late endocrine abnormalities. ACTH deficiency was reported in

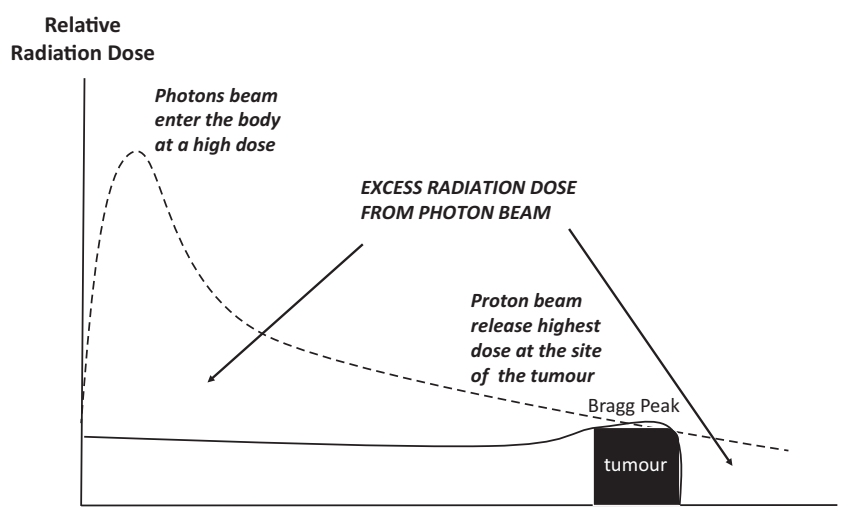

Depth of tissue

Figure 2

Radiation effects from photon vs proton radiotherapy.
$5 \%$ of the cohort, which was not statistically different to those who had conventional photon therapy (Eaton et al. 2016). In a study with a mixed cohort of CNS tumours, Viswanathan et al. compared 19 patients who had proton therapy with 12 conventional plus proton therapy, and reported ACTH deficiency in three patients in each group by LDST (Viswanathan et al. 2011). Abnormalities were detected sooner during follow-up in the conventional radiotherapy plus proton therapy group than in the proton therapy only group (Viswanathan et al. 2011).

\section{Chemotherapy}

Chemotherapy-related transient HPAA dysfunction is reported in the acute periods of treatment in some childhood cancers, but evidence of its long-term effects is minimal.

Published data have shown that HPAA dysfunction is uncommon in childhood cancer survivors of CNS tumours treated without cranial or total body irradiation. Schmiegelow et al. compared HPAA function via ITT and ACTH test in 73 childhood brain tumours with 17 controls and concluded no additional effect from chemotherapy to the impact of cranial irradiation (Schmiegelow et al. 2003). Cochrane et al. reported no cases of cortisol deficiency among 30 childhood cancer survivors with CNS tumours treated with radiation avoiding therapies after a mean of 8 years (Cochrane et al. 2017).

Among survivors of chemotherapy-treated nonCNS tumours, HPAA insufficiency is also rare with the exception of drugs used to treat malignant adrenocorticoid tumours (e.g. mitotane), which can lead to adrenal necrosis and glucocorticoid and mineralocorticoid deficiency. In a cohort of 31 childhood cancer survivors with non-CNS disease treated with chemotherapy only, Rose et al. reported 81\% developed one or more endocrine abnormalities 13 years post treatment, but none had ACTH deficiency (Rose et al. 2004).

\section{Glucocorticoid treatment}

Secondary adrenal insufficiency is common in childhood cancer survivors after prolonged high doses of glucocorticoid therapy and may persist for some time even if treatment is withdrawn gradually. Glucocorticoids are used as part of the treatment protocol for some malignancies such as acute lymphoblastic leukaemia and lymphoma. It may also be given to relieve side-effects of chemotherapy such as vomiting, reduce inflammation such as cerebral oedema associated with intracranial neoplasms and treat graft-vs-host disease after HSCT. 
Transient steroid-induced hypoadrenalism has been reported in up to $67 \%$ of acute lymphoblastic leukaemia survivors post induction and may persist for 8.5 months and longer (Vestergaard et al. 2011). The latest Cochrane review on adrenal insufficiency in childhood acute lymphoblastic leukaemia after glucocorticoid therapy included 10 studies with 298 patients, reported adrenal insufficiency in nearly all children in the first days after cessation of glucocorticoid treatment. While the majority recovered within 7 weeks, a small number of children had ongoing adrenal insufficiency lasting up to 34 weeks. High-dose fluconazole was suggested as a risk factor for prolonged adrenal insufficiency. The relationship between the presence of infection or stress and adrenal insufficiency were not consistent (Rensen et al. 2017).

\section{Immunotherapy}

Immune check point inhibitors are used in the treatment of a number of adult and childhood cancers. These agents block the T-cell-mediated inhibitory signalling pathways by modulating immune check point proteins, such as T-lymphocytes antigen-4 (CTLA-4) and programmed cell death receptor-1 (PD-1), to prevent tumour proliferation (Shankar et al. 1997). However, the inhibitory action may result in several autoimmune side effects including thyroiditis, adrenalitis and hypophysitis. To date, there is minimal evidence in the long-term endocrine effects of immunotherapy in childhood cancer survivors. Data extrapolated from adults treated with immunotherapy reported a prevalence of primary adrenal dysfunction in 0.3-1\% (Joshi et al. 2016).

\section{Oncology treatment and autoimmune diseases}

An increased prevalence of autoimmune diseases has been observed in childhood cancer survivors. An increased production of antibodies due to immune abnormalities after chemotherapy or immunotherapy, and the increased number of infection during cancer treatment have been hypothesised as the potential pathophysiology. A Scandinavian cross-sectional study of 20,000 adult childhood cancer survivors reported a 1.4 increase risk in hospital contacts for an autoimmune disease over background population. Addison's disease was the second most common condition in terms of hospitalisation $(=13.8)$ and absolute excess risk $(=13)$. Significant increase was reported among survivors of leukaemia, Hodgkin's lymphoma, renal tumours and CNS neoplasms. However, given the high \% of CNS tumours in the group, it is possible that some cases of secondary adrenal insufficiency after treatment with glucocorticoids may be incorrectly recorded as Addison's disease (Holmqvist et al. 2016). Childhood-onset autoimmune adrenal disease is extremely rare in cancer survivors, with only one isolated case of primary adrenal insufficiency reported to date, in a 9-year-old child 17 months after busulfan and cyclophosphamide-based conditioning for HSCT (SavasErdeve et al. 2011).

\section{Patient factors}

\section{Time post treatment}

A longitudinal study by Laughton et al. showed that in survivors of childhood embryonic tumours and medulloblastoma, ACTH deficiency was uncommon in the first 6 months after cranial or craniospinal irradiation exposure, but escalates afterwards with a 4-year cumulative incidence of 38\% (Laughton et al. 2008). HPAA abnormalities develop over time in childhood cancer survivors post cranial radiation with an increase in incidence and severity with longer time following treatment (Darzy 2009). Progression may be caused by gradual parenchymal cell loss from degenerative vascular changes and mitotic cell death of capillary endothelial cells as a result of radiation damage (Darzy \& Shalet 2009). Long-term surveillance with serial testing is important in childhood brain tumour survivors at risk to detect lateonset HPAA dysfunction.

\section{Other factors}

Females may be relatively protected from ACTH deficiency in tumours of the hypothalamus and vicinity (Gan et al. 2015). The pathophysiology is unclear, but higher total cortisol levels in female patients on oestrogen replacement may be a possible explanation (the proposed mechanism is discussed in the 'Laboratory considerations in cortisol measurements' section). In terms of age at exposure, while younger age at cranial irradiation was associated with increased risk of growth hormone deficiency in childhood cancer survivors, this has not been shown with cortisol deficiency (Shalitin et al. 2011).

\section{Assessment of HPAA dysfunction in childhood cancer survivors}

Medical history is important although symptoms of HPAA dysfunction may be absent or subtle with fatigue, reduced stamina and poor weight gain, which are generally common in cancer survivors. Therefore, vigilance is 
necessary to ensure those at risk are investigated proactively. It is also important to be aware that ACTH deficiency may co-exist with other pituitary hormone deficiencies and the diagnosis may only be unmasked after the supplementation of these hormones, such as when starting thyroxine, which enhances metabolism and growth hormone that normalises $11 \beta$-hydroxysteroid dehydrogenase type 1 overactivity leading to an increase in the conversion of active cortisol to inactive cortisone (Giavoli et al. 2004). It is therefore important to assess ACTH function and initiate cortisol replacement before other hormones in patients with potential co-existing ACTH deficiency and central hypothyroidism or growth hormone deficiency to prevent the risk of adrenal crisis.

\section{Surveillance guidelines}

Due to the diagnostic challenges in HPAA dysfunction, the timing of the diagnosis has been historically dependent on the referral for endocrine assessment. Therefore, risk stratified surveillance guidelines with evidence-based recommendations on the method, timing and frequency of screening are currently lacking but important to develop for the future. International consensus guidelines on the follow-up of CNS neoplasia and HP dysfunction are under development.

The latest Children's Oncology Group Long-Term Follow-Up Guidelines recommend yearly endocrine evaluation for HPAA dysfunction in survivors if the radiation dose to the HP axis is $>30$ Gy (Children's Oncology Group 2013). This replaces previous recommendations where patients received $>40 \mathrm{~Gy}$ are screened by a yearly 08:00 h cortisol. However, these guidelines do not specify the definition of an endocrine evaluation, and it is unclear whether an early morning cortisol and/or dynamic tests should be included each time. Reassessment of HPAA status after high dose or prolonged courses of steroids needs to allow for a potentially long recovery time. Repeat assessment is essential even up to a couple of years after the completion of oncology treatment, particularly in those who do not have obvious risk factors for long-term HPAA dysfunction, but required glucocorticoid replacement for suboptimal cortisol response in the acute period.

\section{Biochemical investigations}

There are a number of different biochemical tests available to assess HPAA function, and the most appropriate method for each individual relies on clinical judgement. A clear understanding of the principles and limitations of the tests are essential to avoid diagnostic pitfalls. Table 3 summaries the pros and cons of the common investigations used to assess HPAA function in childhood cancer survivors in clinical practice and research.

\section{Baseline (unstimulated) ACTH and cortisol levels}

Early morning (08:00-09:00h) unstimulated cortisol and ACTH levels are often used as a routine screening test for central or secondary adrenal abnormalities. A cortisol level of $>300 \mathrm{mmol} / \mathrm{L}$ has previously been reported to exclude significant ACTH deficiency in patients post radiotherapy (Darzy 2009), but local variations in laboratory assays must be considered. Only an elevated plasma ACTH with an extremely low cortisol level is useful in the context of primary adrenal insufficiency as low ACTH levels may not be measurable and are hence not diagnostic of central deficiency.

There are a number of drawbacks in using early morning ACTH and cortisol levels. Considerable overlap exists between normal individuals and those with adrenal insufficiency (Ranke \& Mullis 2011). Circadian rhythm is not present in the very young under 3 months of age or seriously ill patients. Unstimulated cortisol levels do not necessarily reflect the individuals' response under stress. Finally, ACTH is unstable in blood with a short $(<10-\mathrm{min})$ half-life and samples must be handled appropriately. Therefore, there should be a low threshold in proceeding to dynamic tests in at-risk patients.

\section{Insulin tolerance test}

The ITT allows simultaneous assessment of ACTH and growth hormone function. HPAA assessment using the ITT is based on the principle that hypoglycaemia causes neuroglycopenia, which activates corticotropin-releasing hormone (CRH) secretion from the hypothalamus, enhances ACTH release from the pituitary gland, and in turn, cortisol production. It is considered the gold standard for HPAA assessment, particularly after cranial irradiation, which affects the hypothalamus more than the pituitary gland. However, the ITT raises safety concerns in patients with poor counter regulatory responses to hypoglycaemia, and the test is contraindicated in patients with cardiac diseases and epilepsy. The test must only be carried out in specialised centres by experienced personnel.

\section{ACTH (Synacthen) stimulation test: standard and low dose}

The ACTH stimulation test primarily assesses adrenal cortex function. However, in view of the risk of the ITT, 
Table 3 Summary of investigations for HPAA function.

\begin{tabular}{|c|c|c|}
\hline Test & Pro & Cons \\
\hline Early morning cortisol & $\begin{array}{l}\text { - Easy } \\
\text { - Safe }\end{array}$ & $\begin{array}{l}\text { - Overlap between normal and abnormal } \\
\text { results } \\
\text { - Does not reflect ability to mount response } \\
\text { at stress } \\
\text { - Lack of circadian rhythm in the very young } \\
\text { and sick }\end{array}$ \\
\hline Insulin tolerance test & $\begin{array}{l}\text { - Gold standard post cranial irradiation } \\
\text { - Enable simultaneous assessment of } \\
\text { pituitary ACTH and GH reserve }\end{array}$ & $\begin{array}{l}\text { - Relatively invasive and labour intensive } \\
\text { - Hypoglycaemia risk (contraindicated in } \\
\text { patients with seizures and cardiac disease) }\end{array}$ \\
\hline $\begin{array}{l}\text { ACTH stimulation test (low and } \\
\text { standard dose) }\end{array}$ & $\begin{array}{l}\text { - Low cost } \\
\text { - Relatively safe }\end{array}$ & $\begin{array}{l}\text { - Controversies with dosage (standard vs } \\
\text { low dose) } \\
- \text { Poor sensitivity (standard dose) } \\
\text { - Poor specificity (low dose) } \\
\text { - Anaphylaxis risk (low) } \\
\text { - Lose dose difficult to titrate accuracy }\end{array}$ \\
\hline Corticotropin-releasing hormone test & $\begin{array}{l}\text { - Distinguish hypothalamic to pituitary } \\
\text { abnormalities }\end{array}$ & - ACTH unstable \\
\hline Cortisol profiling & $\begin{array}{l}\text { - Shows physiological circadian rhythm } \\
\text { of cortisol release }\end{array}$ & $\begin{array}{l}\text { - Labour intensive } \\
\text { - Does not reflect ability to mount response } \\
\text { at stress } \\
\text { - Lack of circadian rhythm in the very young } \\
\text { and sick }\end{array}$ \\
\hline
\end{tabular}

it is often used as an alternative in the investigation of secondary adrenal insufficiency, assuming that chronic ACTH deficiency results in atrophy of the adrenal cortex and failure to respond to exogenous corticotrophin. The optimal dose for this purpose is debatable and some advocate the LDST. A retrospective review of childhood cancer survivors who underwent HPAA assessments in childhood cancer survivors reported normal function in $89 \%$ by the standard dose Synacthen stimulation test (SSST) but only 65\% by LDST (Patterson et al. 2009). A systematic review and meta-analysis showed that the LDST $\left(0.5-1 \mu \mathrm{g} / \mathrm{m}^{2}\right.$, maximum $\left.1 \mu \mathrm{g}\right)$ has a higher sensitivity (86\% vs 61\%), but a lower specificity ( $88 \%$ vs $99 \%)$ than the SSST $\left(250 \mu \mathrm{g} / 1.73 \mathrm{~m}^{2}, 250 \mu \mathrm{g} \max \right)$. However, comparisons of the two tests are limited due to the lack of standardisation of assays and protocols with regards to timing, frequency and dose ( $\mathrm{Ng}$ et al. 2016). It can be challenging to titrate the precise dosage for patients of very small size and the test does not distinguish between hypothalamic and pituitary pathologies.

Although the ACTH stimulation test may appear to be a safer and easier option than the ITT for HPAA assessment, false negatives from previous research in childhood cancer survivors raised concerns of cases missed. Schmegelow et al. who evaluated the HPAA with both an ITT and an ACTH test 15 years after treatment for brain tumours showed $30 \%$ of the patients passed the ACTH test, but failed the ITT while no patients passed the ITT and failed the ACTH stimulation test (Schmiegelow et al. 2003). Of note, results of the ACTH stimulation test may be normal in the acute period in patients developing central hypocortisolaemia.

\section{CRH test}

The CRH test assesses the ability of the pituitary gland to secrete ACTH for cortisol production. Patients with pituitary dysfunction show impaired secretion of ACTH and cortisol while those with hypothalamic abnormalities will have an exaggerated and prolonged ACTH response with suboptimal peak cortisol levels. In clinical practice, this test is usually reserved for patients when other tests are contraindicated.

\section{Cortisol profiling}

Twenty-four-hour ACTH and cortisol frequent venous sampling demonstrates the physiological hormone secretion of the HPAA. However, this method is labour intensive and does not assess the individuals' ability to mount a normal response under stress. It is usually reserved for research studies or in some centres dose monitoring in patients on steroid replacement.

\section{Laboratory considerations in cortisol measurements}

Regardless of the method of assessment, it is important to appreciate that cortisol measurements are influenced significantly by the laboratory assay used. 
Older immmunoassays over-estimated results due to interferences from cross-reactivity with corticosterone. New-generation assays have lower acceptable cortisol peak levels as normal. For example, while a peak cortisol level of over $500-550 \mathrm{nmol} / \mathrm{L}$ was historically considered as normal for a SSST, some of the newer cortisol assays produce results closely aligned to mass spectroscopy method with a cut-off of approximately $420 \mathrm{nmol} / \mathrm{L}$ as an adequate response (Hawley et al. 2016).

In addition, other factors may interfere with cortisol measurements. Oral oestrogen, in particular, increases cortisol-binding globulin and hence the total cortisol levels. Therefore, while free cortisol levels are not affected, a higher reference range is needed when interpreting the results reporting total cortisol level (El-Farhan et al. 2013). However, the same problem has not been observed in patients on transdermal oestrogen replacement (Qureshi et al. 2007). This information is important when assessing HPAA function in female childhood cancer survivors as gonadal failure is common and patients may be on sex hormone replacement therapy.

\section{Relationship between HPAA function and wider aspects of health}

There has been increasing research interest in the relationships between HPAA function and wider aspects of health such as chronic physical and psychological stress, neuro-cognition and chronic fatigue syndrome in childhood cancer survivors. Pilot data suggested that the metabolic syndrome in childhood cancer survivors may be associated with alterations in the HPAA suggesting chronic stress (Yeap et al. 2005). Survivors of childhood leukaemia treated without cranial irradiation have demonstrated increased morning cortisol levels with intact endocrine and cardiovascular responses to social stress in the short term (Gordijn et al. 2012, 2013). However, a potential impact of adrenal insufficiency on neurocognitive outcomes has been reported in leukaemia survivors (Cheung et al. 2017). Symptoms that characterise chronic fatigue syndrome and autonomic dysfunction have been described in childhood cancer survivors, which have overlapping features with HPAA dysfunction. Zeller et al. reported reduced levels of plasma ACTH and raised urine noradrenaline in survivors of childhood cancer with chronic fatigue suggesting slight inhibition of the HPAA and enhanced sympathetic nervous system activity, which is similar to non-cancer survivors with chronic fatigue syndrome (Zeller et al. 2014). Long-term alterations in the HPAA and its associated physical, psychological and social consequences, in childhood cancer survivors still require evaluation in larger prospective patient cohorts with longer follow-up time to investigate potential impact on health and quality of life.

\section{Future directions}

Continued systematic longitudinal data collection in all aspects of late effects in childhood cancer at national and international levels is needed to enable oncology treatment related abnormalities to be reported in line with evolving treatment protocols and new modalities. In addition to providing up-to-date information on the prevalence of HPAA abnormalities, outcomes will also highlight risk factors to allow targeted screening in vulnerable patients. There is ongoing debate on the most appropriate methods of screening and confirmatory test to diagnose HPAA dysfunction in childhood cancer survivors. International consensus is needed to standardise the methods and rationalise the frequency of screening to ensure timely and appropriate investigations.

\section{Summary and conclusions}

In summary, HPAA dysfunction is relatively less common compared with other pituitary hormone deficiencies in childhood cancer survivors, but highly significant when it occurs. The incidence and prevalence of HPAA dysfunction reported in the literature are variable due to heterogeneity in patients' characteristics, primary diagnoses and treatment protocols, as well as surveillance methods used to assess HPAA function.

The key clinical messages from this review are

- Clinicians managing childhood cancer survivors must be well informed of their diagnosis and treatment background to appreciate the risk of long-term morbidity for individual patients and tailor appropriate surveillance.

- ACTH deficiency may develop many years after the completion of oncological treatment alongside multiple pituitary hormone deficiencies due to factors such as low-grade tumour progression and evolution of cranial irradiation effects with time.

- In general, childhood cancer survivors most at risk of ACTH deficiency are

o those who had tumours located and/or had surgery performed near the HP region,

o those who received accumulative HP radiotherapy dose of over $30 \mathrm{~Gy}$. 
- As clinical symptoms are often minimal, the diagnosis of HPAA dysfunction may be delayed without routine surveillance and formal assessment.

- It is important to re-evaluate HP function in patients on glucocorticoid replacement, with potential secondary adrenal insufficiency after high-dose or longer term glucocorticoid treatment to ensure treatment is continued or discontinued appropriately.

\section{Declaration of interest}

The authors declare that there is no conflict of interest that could be perceived as prejudicing the impartiality of this review.

\section{Funding}

This work did not receive any specific grant from any funding agency in the public, commercial, or not-for-profit sector.

\section{Author contribution statement}

Both C W and E C C contributed equally in the writing of this manuscript.

\section{References}

Arora RS, Alston RD, Eden TO, Estlin EJ, Moran A \& Birch JM 2009 Ageincidence patterns of primary CNS tumors in children, adolescents, and adults in England. Neuro-Oncology 11 403-413. (https://doi. org/10.1215/15228517-2008-097)

Bölling T, Willich N \& Ernst I 2010 Late effects of abdominal irradiation in children: a review of the literature. Anticancer Research 30 227-231. (https://doi.org/10.1007/s00066-011-2190-1)

Brignardello E, Felicetti F, Castiglione A, Chiabotto P, Corrias A, Fagioli F, Ciccone G \& Boccuzzi G 2013 Endocrine health conditions in adult survivors of childhood cancer: the need for specialized adult-focused follow-up clinics. European Journal of Endocrinology 168 465-472. (https://doi.org/10.1530/EJE-12-1043)

British Neuro-Oncology Society 2011 Rare Brain and CNS Tumour Guidelines. Guidelines on the Diagnosis and Management of Optic Pathway Glioma. British Neuro-Oncology Society. (available at: https://www.bnos.org.uk/wp-content/uploads/2015/08/Opticpathway-glioma-guidelines.pdf)

Campbell J, Wallace W, Bhatti L, Stockton D, Rapson T \& Brewster DH 2004 Childhood Cancer in Scotland: Trends in Incidence, Mortality and Survival 1975-1999. Edinburgh, UK: NHS Scotland Information and Statistics Division.

Chemaitilly W, Li Z, Huang S, Ness KK, Clark KL, Green DM, Barnes N, Armstrong GT, Krasin MJ, Srivastava DK, et al. 2015 Anterior hypopituitarism in adult survivors of childhood cancers treated with cranial radiotherapy: a report from the St Jude Lifetime Cohort study. Journal of Clinical Oncology 33 492-500. (https://doi. org/10.1200/JCO.2014.56.7933)

Cheung YT, Chemaitilly W, Mulrooney DA, Brinkman TM, Liu W, Banerjee P, Srivastava D, Pui CH, Robison LL, Hudson MM, et al. 2017 Association between dehydroepiandrosterone-sulfate and attention in long-term survivors of childhood acute lymphoblastic leukemia treated with only chemotherapy. Psychoneuroendocrinology 76 114-118. (https://doi.org/10.1016/i.psyneuen.2016.11.014)
Children's Oncology Group 2013 Long-Term Follow-Up Guidelines for Survivors of Childhood, Adolescent, and Young Adult Cancer, Version 4. Monrovia, CA, USA: Children's Oncology Group. (available at: http://www.survivorshipguidelines.org/pdf/ LTFUGuidelines_40.pdf)

Clement SC, Meeteren AY, Kremer LC, van Trotsenburg AS, Caron HN \& van Santen HM 2014 High prevalence of early hypothalamicpituitary damage in childhood brain tumor survivors: need for standardized follow-up programs. Pediatric Blood and Cancer 61 2285-2289. (https://doi.org/10.1002/pbc.25176)

Clement SC, Schoot RA, Slater O, Chisholm JC, Abela C, Balm AJM, van den Brekel MW, Breunis WB, Chang YC, Davila Fajardo R, et al. $2016 a$ Endocrine disorders among long-term survivors of childhood head and neck rhabdomyosarcoma. European Journal of Cancer $\mathbf{5 4}$ 1-10. (https://doi.org/10.1016/j.ejca.2015.10.064)

Clement SC, Schouten-van Meeteren AY, Boot AM, Claahsen-van der Grinten HL, Granzen B, Sen Han K, Janssens GO, Michiels EM, van Trotsenburg AS, Vandertop WP, et al. $2016 b$ Prevalence and risk factors of early endocrine disorders in childhood brain tumor survivors: a nationwide, multicenter study. Journal of Clinical Oncology 34 4362-4370. (https://doi.org/10.1200/JCO.2016.67.5025)

Cochrane AM, Cheung C, Rangan K, Freyer D, Nahata L, Dhall G \& Finlay JL 2017 Long-term follow-up of endocrine function among young children with newly diagnosed malignant central nervous system tumors treated with irradiation-avoiding regimens. Pediatric Blood and Cancer 64 e26616. (https://doi.org/10.1002/pbc.26616)

Cohen M, Bartels U, Branson H, Kulkarni AV \& Hamilton J 2013 Trends in treatment and outcomes of pediatric craniopharyngioma, 19752011. Neuro-Oncology 15 767-774. (https://doi.org/10.1093/neuonc/ not026)

Constine LS, Woolf PD, Cann D, Mick G, McCormick K, Raubertas RF \& Rubin P 1993 Hypothalamic-pituitary dysfunction after radiation for brain tumors. New England Journal of Medicine 328 87-94. (https:// doi.org/10.1056/NEJM199301143280203)

Crowne EC, Wallace WH, Gibson S, Moore CM, White A \& Shalet SM 1993 Adrenocorticotrophin and cortisol secretion in children after low dose cranial irradiation. Clinical Endocrinology 39 297-305. (https://doi.org/10.1111/j.1365-2265.1993.tb02369.x)

Darzy KH 2009 Radiation-induced hypopituitarism after cancer therapy: who, how and when to test. Nature Clinical Practice: Endocrinology and Metabolism 5 88-99. (https://doi.org/10.1038/ncpendmet1051)

Darzy KH \& Shalet SM 2009 Hypopituitarism following radiotherapy revisited. Endocrine Development 15 1-24.

Diller L, Chow EJ, Gurney JG, Hudson MM, Kadin-Lottick NS, Kawashima TI, Leisenring WM, Meacham LR, Mertens AC, Mulrooney DA, et al. 2009 Chronic disease in the Childhood Cancer Survivor Study cohort: a review of published findings. Journal of Clinical Oncology 27 2339-2355. (https://doi.org/10.1200/ JCO.2008.21.1953)

Eaton BR, Esiashvili N, Kim S, Patterson B, Weyman EA, Thornton LT, Mazewski C, MacDonald TJ, Ebb D, MacDonald SM, et al. 2016 Endocrine outcomes with proton and photon radiotherapy for standard risk medulloblastoma. Neuro-Oncology 18 881-887. (https:// doi.org/10.1093/neuonc/nov302)

El-Farhan N, Pickett A, Ducroq D, Bailey C, Mitchem K, Morgan N, Armston A, Jones L, Evans C \& Rees DA 2013 Method-specific serum cortisol responses to the adrenocorticotrophin test: comparison of gas chromatography-mass spectrometry and five automated immunoassays. Clinical Endocrinology 78 673-680. (https://doi. org/10.1111/cen.12039)

Follin C, Wiebe T, Moell C \& Erfurth EM 2014 Moderate dose cranial radiotherapy causes central adrenal insufficiency in long-term survivors of childhood leukaemia. Pituitary 17 7-12. (https://doi. org/10.1007/s11102-012-0459-8)

Gan HW, Phipps K, Aquilina K, Gaze MN, Hayward R \& Spoudeas HA 2015 Neuroendocrine morbidity after pediatric optic gliomas: (c) 2018 Society for Endocrinology Published by Bioscientifica Ltd. Printed in Great Britain 
a longitudinal analysis of 166 children over 30 years. Journal of Clinical Endocrinology and Metabolism 100 3787-3799. (https://doi. org/10.1210/jc.2015-2028)

Garwicz S, Anderson H, Olsen JH, Winther JF, Sankila R, Langmark F, Tryggvadottir L, Moller TR, Association of the Nordic Cancer Registries \& Nordic Society for Pediatric Hematology Oncology 2012 Late and very late mortality in 5-year survivors of childhood cancer: changing pattern over four decades - experience from the Nordic countries. International Journal of Cancer 131 1659-1666. (https://doi. org/10.1002/ijc.27393)

Giavoli C, Libe R, Corbetta S, Ferrante E, Lania A, Arosio M, Spada A \& Beck-Peccoz P 2004 Effect of recombinant human growth hormone (GH) replacement on the hypothalamic-pituitary-adrenal axis in adult GH-deficient patients. Journal of Clinical Endocrinology and Metabolism 89 5397-5401. (https://doi.org/10.1210/jc.2004-1114)

Gordijn MS, van Litsenburg RR, Gemke RJ, Bierings MB, Hoogerbrugge PM, van de Ven PM, Heijnen CJ \& Kaspers GJ 2012 Hypothalamic-pituitary-adrenal axis function in survivors of childhood acute lymphoblastic leukemia and healthy controls. Psychoneuroendocrinology 37 1448-1456. (https://doi.org/10.1016/j. psyneuen.2012.01.014)

Gordijn MS, Gemke RJ, Bierings MB, Hoogerbrugge PM, TersteegKamperman MD, Heijnen CJ, Rotteveel J \& Kaspers GJ 2013 Adequate endocrine and cardiovascular response to social stress in survivors of childhood acute lymphoblastic leukemia. Psychoneuroendocrinology 38 3145-3149. (https://doi.org/10.1016/j. psyneuen.2013.07.013)

Hawley JM, Owen LJ, Lockhart SJ, Monaghan PJ, Armston A, Chadwick CA, Wilshaw H, Freire M, Perry L \& Keevil BG 2016 Serum cortisol: an up-to-date assessment of routine assay performance. Clinical Chemistry 62 1220-1229. (https://doi.org/10.1373/ clinchem.2016.255034)

Heikens J, Michiels EM, Behrendt H, Endert E, Bakker PJ \& Fliers E 1998 Long-term neuro-endocrine sequelae after treatment for childhood medulloblastoma. European Journal of Cancer 34 1592-1597. (https:// doi.org/10.1016/S0959-8049(98)00212-3)

Holmqvist AS, Olsen JH, Mellemkjaer L, Garwicz S, Hjorth L, Moell C, Mansson B, Tryggvadottir L, Hasle H, Winther JF, et al. 2016 Autoimmune diseases in Adult Life after Childhood Cancer in Scandinavia (ALiCCS). Annals of the Rheumatic Diseases $\mathbf{7 5}$ 1622-1629. (https://doi.org/10.1136/annrheumdis-2015-207659)

Jones L, Hoban P \& Metcalfe P 2001 The use of the linear quadratic model in radiotherapy: a review. Australasian Physical and Engineering Science in Medicine 24 132-146. (https://doi.org/10.1007/ BF03178355

Joshi MN, Whitelaw BC, Palomar MT, Wu Y \& Carroll PV 2016 Immune checkpoint inhibitor-related hypophysitis and endocrine dysfunction: clinical review. Clinical Endocrinology 85 331-339. (https://doi.org/10.1111/cen.13063)

Laughton SJ, Merchant TE, Sklar CA, Kun LE, Fouladi M, Broniscer A, Morris EB, Sanders RP, Krasin MJ, Shelso J, et al. 2008 Endocrine outcomes for children with embryonal brain tumors after riskadapted craniospinal and conformal primary-site irradiation and high-dose chemotherapy with stem-cell rescue on the SJMB-96 trial. Journal of Clinical Oncology 26 1112-1118. (https://doi.org/10.1200/ JCO.2008.13.5293)

Livesey EA, Hindmarsh PC, Brook CG, Whitton AC, Bloom HJ, Tobias JS, Godlee JN \& Britton J 1990 Endocrine disorders following treatment of childhood brain tumours. British Journal of Cancer $\mathbf{6 1}$ 622-625. (https://doi.org/10.1038/bjc.1990.138)

Mertens AC, Liu Q, Neglia JP, Wasilewski K, Leisenring W, Armstrong GT, Robison LL \& Yasui Y 2008 Cause-specific late mortality among 5-year survivors of childhood cancer: the Childhood Cancer Survivor Study. Journal of the National Cancer Institute 100 1368-1379. (https://doi.org/10.1093/jnci/djn310)
Mostoufi-Moab S \& Grimberg A 2010 Pediatric brain tumor treatment: growth consequences and their management. Pediatric Endocrinology Reviews 8 6-17.

Mostoufi-Moab S, Seidel K, Leisenring WM, Armstrong GT, Oeffinger KC, Stovall M, Meacham LR, Green DM, Weathers R, Ginsberg JP, et al. 2016 Endocrine abnormalities in aging survivors of childhood cancer: a report from the Childhood Cancer Survivor Study. Journal of Clinical Oncology 34 3240-3247. (https://doi.org/10.1200/ JCO.2016.66.6545)

Ng SM, Agwu JC \& Dwan K 2016 A systematic review and meta-analysis of Synacthen tests for assessing hypothalamic-pituitary-adrenal insufficiency in children. Archives of Disease in Childhood 101 847-853. (https://doi.org/10.1136/archdischild-2015-308925)

Oberfield SE, Nirenberg A, Allen JC, Cohen H, Donahue B, Prasad V, Schiff R, Pang S, Ghavimi F, David R, et al. 1997 Hypothalamicpituitary-adrenal function following cranial irradiation. Hormone Research 47 9-16. (https://doi.org/10.1159/000185357)

Oeffinger KC, Mertens AC, Sklar CA, Kawashima T, Hudson MM, Meadows AT, Friedman DL, Marina N, Hobbie W, Kadan-Lottick NS, et al. 2006 Chronic health conditions in adult survivors of childhood cancer. New England Journal of Medicine 355 1572-1582. (https://doi.org/10.1056/NEJMsa060185)

Patterson BC, Truxillo L, Wasilewski-Masker K, Mertens AC \& Meacham LR 2009 Adrenal function testing in pediatric cancer survivors. Pediatric Blood and Cancer 53 1302-1307. (https://doi. org/10.1002/pbc.22208)

Patterson BC, Wasilewski-Masker K, Ryerson AB, Mertens A \& Meacham L 2012 Endocrine health problems detected in 519 patients evaluated in a pediatric cancer survivor program. Journal of Clinical Endocrinology and Metabolism 97 810-818. (https://doi. org/10.1210/jc.2011-2104)

Paulino AC 2013 Treatment strategies to reduce radiotherapy late effects in children. Journal of Radiation Oncology 2 121-128. (https://doi. org/10.1007/s13566-012-0075-2)

Qureshi AC, Bahri A, Breen LA, Barnes SC, Powrie JK, Thomas SM \& Carroll PV 2007 The influence of the route of oestrogen administration on serum levels of cortisol-binding globulin and total cortisol. Clinical Endocrinology 66 632-635. (https://doi. org/10.1111/j.1365-2265.2007.02784.x)

Ramanauskiene E, Labanauskas L, Verkauskiene R \& Sileikiene R 2014 Early development of endocrine and metabolic consequences after treatment of central nervous system tumors in children. Medicina $\mathbf{5 0}$ 275-280. (https://doi.org/10.1016/j.medici.2014.10.006)

Ranke MB \& Mullis PE 2011 Diagnostics of endocrine function in children and adolescents, 4th edn, pp 357. Basel, Switzerland: Karger.

Rensen N, Gemke RJ, van Dalen EC, Rotteveel J \& Kaspers GJ 2017 Hypothalamic-pituitary-adrenal (HPA) axis suppression after treatment with glucocorticoid therapy for childhood acute lymphoblastic leukaemia. Cochrane Database of Systematic Reviews $\mathbf{1 1}$ CD008727.

Reulen RC, Winter DL, Frobisher C, Lancashire ER, Stiller CA, Jenney ME, Skinner R, Stevens MC, Hawkins MM \& British Childhood Cancer Survivor Study Steering Group 2010 Long-term cause-specific mortality among survivors of childhood cancer. JAMA 304 172-179. (https://doi.org/10.1001/jama.2010.923)

Rose SR, Schreiber RE, Kearney NS, Lustig RH, Danish RK, Burghen GA \& Hudson MM 2004 Hypothalamic dysfunction after chemotherapy. Journal of Pediatric Endocrinology and Metabolism 17 55-66.

Rose SR, Danish RK, Kearney NS, Schreiber RE, Lustig RH, Burghen GA \& Hudson MM 2005 ACTH deficiency in childhood cancer survivors. Pediatric Blood and Cancer 45 808-813. (https://doi.org/10.1002/ pbc.20327)

Royal College of Radiologists 2016 Paediatric Cancer. In Radiotherapy Dose Fractionation, Ch 9, pp 66-76. London, UK: The Royal College
(C) 2018 Society for Endocrinology Published by Bioscientifica Ltd. Printed in Great Britain 
of Radiologists. (available at: https://www.rcr.ac.uk/system/files/ publication/field_publication_files/bfco163_9_paediatric.pdf)

Savas-Erdeve S, Berberoglu M, Siklar Z, Hacihamdioglu B, Ocal G, Ertem M, Ileri T, Ince EU \& Uysal Z 2011 Primary adrenal insufficiency in a child after busulfan and cyclophosphamide-based conditioning for hematopoietic stem cell transplantation. Journal of Pediatric Endocrinology and Metabolism 24 853-855.

Schmiegelow M, Lassen S, Poulsen HS, Feldt-Rasmussen U, Schmiegelow K, Hertz H \& Muller J 2000 Cranial radiotherapy of childhood brain tumours: growth hormone deficiency and its relation to the biological effective dose of irradiation in a large population based study. Clinical Endocrinology 53 191-197. (https:// doi.org/10.1046/j.1365-2265.2000.01079.x)

Schmiegelow M, Feldt-Rasmussen U, Rasmussen AK, Lange M, Poulsen HS \& Muller J 2003 Assessment of the hypothalamo-pituitary-adrenal axis in patients treated with radiotherapy and chemotherapy for childhood brain tumor. Journal of Clinical Endocrinology and Metabolism 88 3149-3154. (https://doi.org/10.1210/jc.2002-021994)

Shalitin S, Gal M, Goshen Y, Cohen I, Yaniv I \& Phillip M 2011 Endocrine outcome in long-term survivors of childhood brain tumors. Hormone Research in Paediatrics 76 113-122. (https://doi. org/10.1159/000327584)

Shankar RR, Jakacki RI, Haider A, Lee MW \& Pescovitz OH 1997 Testing the hypothalamic-pituitary-adrenal axis in survivors of childhood brain and skull-based tumors. Journal of Clinical Endocrinology and Metabolism 82 1995-1998.

Spoudeas HA, Charmandari E \& Brook CG 2003 Hypothalamo-pituitaryadrenal axis integrity after cranial irradiation for childhood posterior fossa tumours. Medical and Pediatric Oncology 40 224-229. (https:// doi.org/10.1002/mpo.10267)
Tan TS, Patel L, Gopal-Kothandapani JS, Ehtisham S, Ikazoboh EC, Hayward R, Aquilina K, Skae M, Thorp N, Pizer B, et al. 2017 The neuroendocrine sequelae of paediatric craniopharyngioma: a 40-year meta-data analysis of 185 cases from three UK centres. European Journal of Endocrinology 176 359-369. (https://doi.org/10.1530/EJE16-0812)

van Waas M, Neggers SJ, van Eck JP, van Noesel MM, van der Lely AJ, de Jong FH, Pieters R \& van den Heuvel-Eibrink MM 2012 Adrenal function in adult long-term survivors of nephroblastoma and neuroblastoma. European Journal of Cancer 48 1159-1166. (https:// doi.org/10.1016/i.ejca.2012.02.046)

Vestergaard TR, Juul A, Lausten-Thomsen U, Lausen B, Hjalgrim H, Kvist TK, Andersen EW \& Schmiegelow K 2011 Duration of adrenal insufficiency during treatment for childhood acute lymphoblastic leukemia. Journal of Pediatric Hematology/Oncology 33 442-449. (https://doi.org/10.1097/MPH.0b013e3182260cbe)

Viswanathan V, Pradhan KR \& Eugster EA 2011 Pituitary hormone dysfunction after proton beam radiation therapy in children with brain tumors. Endocrine Practice 17 891-896. (https://doi. org/10.4158/EP10391.OR)

Yeap M, Elson R, Cornish J, Oakhill A, Lightman S \& Crowne E 2005 Flattened salivary cortisol circadian rhythm in survivors of leukaemia bone marrow transplantation (BMT). In 33rd Meeting of the British Society of Paediatric Endocrinology and Diabetes, p 43. Bristol, UK: BSPED.

Zeller B, Ruud E, Havard Loge J, Kanellopoulos A, Hamre H, Godang K \& Bruun Wyller V 2014 Chronic fatigue in adult survivors of childhood cancer: associated symptoms, neuroendocrine markers, and autonomic cardiovascular responses. Psychosomatics 55 621-629. (https://doi.org/10.1016/j.psym.2013.12.005)

Received in final form 29 April 2018

Accepted 23 May 2018 http://erc.endocrinology-journals.org https://doi.org/10.1530/ERC-18-0217 (c) 2018 Society for Endocrinology Published by Bioscientifica Ltd. Printed in Great Britain 